\title{
Oscillometric and spirometric bronchodilator response in preschool children with and without asthma
}

\author{
Youn Ho Shin Prof $M D^{1}$, Sun Jung Jang $M D^{1}$, Jung Won Yoon $M D^{1}$, Hye Mi Jee Prof $M D^{1}$, \\ Sun Hee Choi Prof MD PhD², Hye Yung Yum MD PhD ${ }^{3}$, David Warburton Prof MD PhD ${ }^{4}$, Man Yong Han Prof $\mathrm{MD}^{1}$
}

\begin{abstract}
YH Shin, SJ Jang, JW Yoon, et al. Oscillometric and spirometric bronchodilator response in preschool children with and without asthma. Can Respir J 2012;19(4):273-277.
\end{abstract}

BACKGROUND: Bronchodilator responses (BDR) are routinely used in the diagnosis and management of asthma; however, their acceptability and repeatability have not been evaluated using quality control criteria for preschool children.

OBJECTIVES: To compare conventional spirometry with an impulse oscillometry system (IOS) in healthy and asthmatic preschool children. METHODS: Data from 30 asthmatic children and 29 controls (two to six years of age) who underwent IOS and spirometry before and after salbutamol administration were analyzed.

RESULTS: Stable asthmatic subjects significantly differed versus controls in their spirometry-assessed BDR (forced expiratory volume in $1 \mathrm{~s}\left[\mathrm{FEV}_{1}\right]$, forced vital capacity and forced expiratory flow at $25 \%$ to $75 \%$ of forced vital capacity) as well as their IOS-assessed BDR (respiratory resistance at $5 \mathrm{~Hz}\left[\mathrm{Rrs}_{5}\right]$, respiratory reactance at $5 \mathrm{~Hz}$ and area under the reactance curve). However, comparisons based on the area under the ROC curve for $\Delta \mathrm{FEV}_{1} \%$ initial versus $\Delta \mathrm{Rrs}_{5} \%$ initial were $0.82(95 \% \mathrm{CI} 0.71$ to 0.93$)$ and 0.75 ( $95 \%$ CI 0.62 to 0.87 ), respectively. Moreover, the sensitivity and specificity for $\Delta \mathrm{FEV}_{1} \geq 9 \%$ were 0.53 and 0.93 , respectively. Importantly, sensitivity increased to 0.63 when either $\Delta \mathrm{FEV}_{1} \geq 9 \%$ or $\Delta \mathrm{Rrs}_{5} \geq 29 \%$ was considered as an additional criterion for the diagnosis of asthma.

CONCLUSION: The accuracy of asthma diagnosis in preschool children may be increased by combining spirometry with IOS when measuring BDR.

Key Words: Asthma; Bronchodilator agents; Oscillometry; Preschool; Spirometry

\footnotetext{
ccording to the National Asthma Education and Prevention A Program guidelines published by the National Heart, Lung and Blood Institute (1), spirometry, including baseline forced expiratory volume in $1 \mathrm{~s}\left(\mathrm{FEV}_{1}\right)$ and the bronchodilator response (BDR) to shortacting beta agonists, should be performed in children as objective measures to establish the diagnosis and severity of bronchial asthma. Although spirometry is considered to be the 'gold standard' for pulmonary function testing (PFT), it has drawbacks including the need for forced maximal inhalation and expiratory breathing manoeuvres that influence airway calibre $(2,3)$, and problems meeting quality control standards, especially in preschool children (4). For preschool children, recent studies have suggested various BDR cut-off points obtained using spirometry $(5,6)$.

Due to the difficulty of performing spirometry on preschool children, other objective outcome measures that can be easily used in young children would be of great value. The impulse oscillometry system (IOS) has been developed as a sensitive, rapid technique that requires only passive patient cooperation (7). Data are available on bronchodilation tests using the IOS in asthmatic children $<6$ years of age $(8-10)$. However, there is no consensus on which BDR cut-off
}

\author{
La réponse bronchodilatatrice à l'oscillométrie et à la \\ spirométrie chez des enfants d'âge préscolaire \\ asthmatiques et non asthmatiques
} HISTORIQUE : On recourt systématiquement aux réponses bronchodilatatri-
ces (RBD) pour diagnostiquer et prendre en charge l'asthme. Cependant, on n'a
pas utilisé de critères de contrôle de la qualité pour évaluer leur acceptabilité et
leur reproductibilité chez les enfants d'âge préscolaire.
OBJECTIFS : Comparer la spirométrie classique à un système d'oscillométrie par
impulsion (SOI) chez des enfants d'âge préscolaire en santé et asthmatiques.
MÉTHODOLOGIE : Les chercheurs ont analysé les données provenant de
30 enfants asthmatiques et de 29 sujets témoins (de deux à six ans) qui ont été
soumis à un SOI et à une spirométrie avant et après l'administration de salbu-
tamol.

RÉSULTATS : La RBD des sujets asthmatiques stables, évaluée par spirométrie, différait considérablement de celles des sujets témoins (volume expiratoire maximal par seconde [VEMS], capacité vitale forcée et débit expiratoire forcé de $25 \%$ à $75 \%$ de la capacité vitale forcée) ainsi que leur RBD évaluée par SOI (résistance respiratoire à $5 \mathrm{~Hz}$ [Rrs5], réactance respiratoire à $5 \mathrm{~Hz}$ et surface sous la courbe de réactance). Cependant, les comparaisons fondées sur la surface sous la courbe caractéristiques de la performance d'un test (ROC) pour une $\triangle$ VEMS initiale par rapport à une $\triangle$ Rrs initiale de $5 \%$ s'élevaient à 0,82 $(95 \%$ IC 0,71 à 0,93$)$ et à 0,75 (95\% IC 0,62 à 0,87), respectivement. De plus, la sensibilité et la spécificité de la $\triangle$ VEMS égale ou supérieure à $9 \%$ étaient de 0,53 et de 0,93 , respectivement. Fait important, la sensibilité passait à 0,63 lorsque la $\triangle$ VEMS égale ou supérieure à $9 \%$ ou la $\Delta \operatorname{Rrs} 5$ égale ou supérieure à 29 \% était considérée comme un critère additionnel pour poser un diagnostic d'asthme.

CONCLUSION : Il est possible de rendre le diagnostic d'asthme plus précis chez les enfants d'âge préscolaire en combinant la spirométrie au SOI pour mesurer la RBD.

point best distinguishes preschool children with asthma from those without asthma on the basis of IOS measurments. Previous studies comparing the two techniques on the basis of BDR in this age group demonstrated that IOS was better than spirometry at discriminating between preschool children with and without asthma $(11,12)$, or simply showed correlations between IOS and spirometry (13). However, none of these previous studies reported quality control results for spirometric measurements $(14,15)$.

Therefore, the aims of the present study were to compare spirometry parameters with IOS parameters in a population of control subjects and asthmatic preschool children using the quality control criteria proposed by Neve et al (15), and to determine whether BDR results increase confidence in diagnosing asthma when BDR results obtained by conventional spirometry are combined with those obtained by IOS.

\section{Patients}

\section{METHODS}

The source population consisted of 567 preschool children from four different day care centres who were originally enrolled in a study to assess reference values for respiratory system impedance using IOS in

${ }^{1}$ Department of Pediatrics, CHA University School of Medicine, Seongnam; ${ }^{2}$ Department of Pediatrics, Kyung Hee University College of

Medicine; 3 Atopy Clinic, Seoul Medical Center, Seoul, Republic of Korea; ${ }^{4}$ Developmental Biology and Regenerative Medicine Program Saban

Research Institute, Children's Hospital Los Angeles, Keck School of Medicine and Ostrow School of Dentistry, Los Angeles, California, USA.

Correspondence: Dr Man Yong Han, Department of Pediatrics, CHA University School of Medicine, 351 Yatap-dong,

Bundang-gu, Seongnam, Gyonggi-do 463-712, Republic of Korea. Telephone 82-31-780-6262, fax 82-31-780-5239, e-mail drmesh@gmail.com 


\begin{tabular}{|c|c|c|c|c|}
\hline Parameter & $\begin{array}{c}\text { Stable } \\
\text { asthma }\end{array}$ & Controls & $95 \% \mathrm{Cl}$ & $\mathbf{P}$ \\
\hline Age, years & $4.6 \pm 0.4$ & $4.6 \pm 0.3$ & & 0.732 \\
\hline Sex, (male/female), $\mathrm{n} / \mathrm{n}$ & $14 / 16$ & $14 / 15$ & & 0.616 \\
\hline Height, cm & $110.6 \pm 9.8$ & $108.7 \pm 5.9$ & & 0.371 \\
\hline Weight, kg & $19.9 \pm 4.6$ & $18.4 \pm 3.3$ & & 0.160 \\
\hline \multicolumn{5}{|l|}{ Spirometry } \\
\hline $\mathrm{FEV}_{1}, \mathrm{~L}$ & $1.0 \pm 0.3$ & $1.0 \pm 0.2$ & -0.13 to 0.17 & 0.775 \\
\hline $\mathrm{FEV}_{1}, \%$ predicted & $102.3 \pm 26.2$ & $96.2 \pm 14.4$ & -0.18 to 0.05 & 0.269 \\
\hline FVC, L & $1.1 \pm 0.4$ & $1.1 \pm 0.3$ & -0.20 to 0.14 & 0.704 \\
\hline FVC, \% predicted & $119.1 \pm 32.0$ & $111.5 \pm 17.3$ & -0.21 to 0.06 & 0.263 \\
\hline $\mathrm{FEV}_{1} / \mathrm{FVC}, \%$ & $89.9 \pm 6.5$ & $93.7 \pm 4.0$ & 1.00 to 6.63 & 0.009 \\
\hline $\mathrm{FEF}_{25-75} / \mathrm{FVC}, \%$ & $102.0 \pm 23.1$ & $135.6 \pm 33.5$ & 18.7 to 48.6 & $<0.001$ \\
\hline \multicolumn{5}{|c|}{ Impulse oscillation system } \\
\hline $\mathrm{Rrs}_{5}, \mathrm{kPa} \cdot \mathrm{s} \cdot \mathrm{L}^{-1}$ & $1.10 \pm 0.30$ & $0.99 \pm 0.21$ & -0.238 to 0.030 & 0.126 \\
\hline $\mathrm{Rrs}_{5}, \%$ predicted & $88.3 \pm 20.3$ & $90.1 \pm 16.0$ & -0.08 to 0.11 & 0.711 \\
\hline $\mathrm{Xrs}_{5}, \mathrm{kPa} \cdot \mathrm{s} \cdot \mathrm{L}^{-1}$ & $-0.42 \pm 0.18$ & $-0.34 \pm 0.13$ & 0.001 to 0.169 & 0.046 \\
\hline $\mathrm{Xrs}_{5}, \%$ predicted & $-34.4 \pm 8.3$ & $-35.5 \pm 5.5$ & -0.05 to 0.03 & 0.532 \\
\hline
\end{tabular}

Data presented as mean $\pm S D$ unless otherwise indicated. Spirometric measurements (forced expiratory volume in $1 \mathrm{~s}\left[F E V_{1}\right]$, forced expiratory flow at $25 \%$ to $75 \%\left[\mathrm{FEF}_{25-75}\right]$ of forced vital capacity [FVC], and FVC) are presented as per cent predicted or initial values. Comparisons attaining a level of significance of at least 0.05 are indicated in bold. IOS measurements are expressed as resistance and reactance at $5 \mathrm{~Hz} \mathrm{FEF}$ 25-75. $\mathrm{Rrs}_{5}$ Respiratory resistance at $5 \mathrm{~Hz} ; \mathrm{Xrs}_{5}$ Respiratory reactance at $5 \mathrm{~Hz}$

Korean preschool children (16). The children underwent IOS and spirometry with an interval of one week at each day care centre. Before PFT, their parents answered the Korean version (17) of the International Study of Asthma and Allergies in Childhood questionnaire, which also included questions to determine whether the subject is considered 'healthy' as defined by Stocks et al (18). Based on questionnaire responses, 40 children were excluded, four of whom according to the criteria of Stocks et al (18). In addition, 378 children with risk factors that may have influenced bronchial reactivity, such as a history of wheezing, atopic dermatitis or allergic rhinitis (19), or a family history of asthma (20), were also excluded. A total of 149 'healthy' controls were able to produce technically acceptable measurements for IOS and spirometry. The childrens' parents were subsequently asked to enroll in the study and visit the institution to undergo BDR testing. Of these, 32 accepted the proposal and three children failed to fulfill the quality-control criteria of Neve et al (15), thus yielding a total of 29 control subjects. During enrollment of the healthy controls, 30 children, two to six years of age who had been diagnosed with asthma and followed at the institution, were enrolled in the study. All patients were well controlled with asthma medications, with a mean $( \pm$ SD) duration of asthma treatment of $21 \pm 14$ months. For asthma severity, symptom frequency (daytime symptoms, night-time awakenings, short-acting beta 2 -agonist use for symptom control and interference with normal activity) was used to classify severity of asthma as defined by the National Asthma Education and Prevention Program/Expert Panel Report-3 guidelines (1). Asthma was intermittent in four (13\%) participants, mildly persistent in 17 (57\%) and moderate-severe persistent in nine $(30 \%)$. Short- and long-acting beta 2 -agonists were withheld for at least $8 \mathrm{~h}$ and $24 \mathrm{~h}$, respectively, before the bronchodilator (reversibility) tests were performed. Anthropometric data, such as height and weight, were measured. The study was approved by the ethics committee of the CHA University (Seongnam, Korea) and written informed consent was obtained from the parents of all participating children.

\section{PFT}

Impulse oscillometry was performed using the Master Screen Spirometry-IOS Digital System (Jaeger, Germany) according to methods described in previous studies $(11,13)$. Spirometric measurements were also performed using the same device according to previous studies $(14,15,21,22)$. Computer incentive games have recently been added to spirometry software and, accordingly, young children included in the present study were trained to perform rapid forced expiration manoeuvres by blowing out candles or prolong expiration by throwing balls in a bowling alley (15). IOS requires the participant to breathe normally through the IOS measuring head, with artificial pressure impulses being superimposed on the tidal breathing of the subject for a short period. Manual occlusion of the nares was implemented to prevent nasal breathing and inhibit the applied pressure oscillations from escaping through the nares. A technician gently held the sides of each child's face to decrease the shunt compliance of the cheeks while the child breathed normally into the mouthpiece to compensate for the compliance of the cheeks (23). After baseline measurements, four puffs of salbutamol $(400 \mu \mathrm{g})$ were administered with a metered dose inhaler and spacer device. All tests were performed in the same sequence as the baseline test and 15 min after administration of salbutamol. A minimum of three technically acceptable measurements were performed with IOS and spirometry before and after administration of salbutamol. Data for spirometry and IOS measurements were collected before and after bronchodilator administration. All values were compared between the two study groups using the absolute change in actual data from the baseline value ( $\Delta$ abs [in L]); the per cent change of actual data from the initial baseline value ( $\Delta \%$ init), which was calculated using the following formula:

$$
100 \times(\text { postvalue }- \text { baseline value)/(baseline value) }
$$

; and the per cent change of actual data from predicted value of baseline $(\Delta \%$ pred $)$, which was calculated using the following formula:

$100 \times($ postvalue - baseline value)/(predicted value of baseline)

The predicted values for the IOS measurements were calculated according to a report by Dencker et al (24). The study by Waalkens et al (25) recommended using the percentage change of the predicted value ( $\Delta \%$ pred) for a particular measure as the index of BDR in children based on the concept that this method is independent of age, height and initial lung function. It was decided to present three different indexes because data comparing measurements of BDR with these methods of PFT in preschool children are lacking. For the sake of simplicity, $\Delta \%$ init was preferred as a description of BDR. A welltrained technician, with two years' experience with PFT, performed the test along with a physician who supervised the process.

\section{Data analysis}

Data are expressed as mean \pm SD unless otherwise indicated. Data were analyzed using PASW version 17.0 (PASW Statistics, USA). The Student's $t$ test was used to compare data between groups. ROC curves were plotted for all possible combinations between the trueand false-positive ratio as the definition of positivity was varied. Cross tabulations were used to generate the sensitivity and specificity of the cut-off values for BDR. $\mathrm{P} \leq 0.05$ was considered to be statistically significant.

\section{RESULTS}

The 59 enrolled subjects were all Korean preschool children. Table 1 summarizes the characteristics and predicted and initial values of lung function of children with and without asthma. Before bronchodilator use, there was a significant difference in baseline respiratory reactance at $5 \mathrm{~Hz}\left(\mathrm{Xrs}_{5}\right)$ and area under the reactance curve (AX), but no difference in baseline respiratory resistance at $5 \mathrm{~Hz}\left(\mathrm{Rrs}_{5}\right), \mathrm{Rrs}_{5} \%$ predicted, $\mathrm{Xrs}_{5} \%$ predicted and resonant frequency $\left(\mathrm{Rf}_{\mathrm{o}}\right)$ in parameters of IOS and significant differences in $\mathrm{FEV}_{1} /$ forced vital capacity (FVC) and forced expiratory flow at $25 \%$ and $75 \%$ of $\mathrm{FVC}\left(\mathrm{FEF}_{25-75}\right) / \mathrm{FVC}$, but no difference in baseline $\mathrm{FEV}_{1}, \mathrm{FEV}_{1} \%$ predicted, baseline FVC, FVC 
TABLE 2

Spirometry and impulse oscillation system (IOS) measurements of bronchodilator response in children with and without asthma (values given as percentage of the initial values)

\begin{tabular}{lccc}
\hline Parameter & Stable asthma & Controls & P \\
\hline Spirometry & & & \\
$\Delta \mathrm{FEV}_{0.5}, \%$ & $16.56(12.14$ to 20.97$)$ & $6.11(3.30$ to 8.92$)$ & $<\mathbf{0 . 0 0 1}$ \\
$\Delta \mathrm{FEV}_{0.75}, \%$ & $14.05(10.12$ to 17.98$)$ & $3.67(1.65$ to 5.68$)$ & $<0.001$ \\
$\Delta \mathrm{FEV}_{1}, \%$ & $11.63(8.01$ to 15.25$)$ & $2.45(0.66$ to 4.25$)$ & $<\mathbf{0 . 0 0 1}$ \\
$\Delta \mathrm{FVC}, \%$ & $9.54(4.92$ to 14.17$)$ & $0.84(-1.32$ to 2.99$)$ & $\mathbf{0 . 0 0 1}$ \\
$\Delta \mathrm{FEF}_{25-75}, \%$ & $30.33(20.34$ to 40.32$)$ & $13.97(7.64$ to 20.31$)$ & $\mathbf{0 . 0 0 8}$ \\
IOS & & & \\
$\Delta \mathrm{Rrs}_{5}(\%)$ & $-24.08(-27.58$ to -20.59$)$ & $-15.55(-18.98$ to -12.13$)$ & $<\mathbf{0 . 0 0 1}$ \\
$\Delta \mathrm{Xrs}_{5}(\%)$ & $52.9(18.1$ to 87.7$)$ & $15.2(5.8$ to 24.7$)$ & $\mathbf{0 . 0 3 3}$ \\
$\Delta \mathrm{AX}(\%)$ & $-49.4(-56.9$ to -41.8$)$ & $-36.1(-46.2$ to -26.0$)$ & $\mathbf{0 . 0 2 6}$ \\
$\Delta \mathrm{Rf}_{\mathrm{O}}(\%)$ & $-18.55(-22.13$ to -14.96$)$ & $-14.48(-18.85$ to -10.11$)$ & 0.084 \\
\hline
\end{tabular}

Data presented as mean (95\% Cl) unless otherwise indicated. Comparisons attaining a level of significance of at least 0.05 are indicated in bold. IOS measurements are given as resistance and reactance at $5 \mathrm{~Hz}$, low-frequency reactance area $(A X)$ and resonant frequency $\left(R f_{o}\right)$. FEF $F_{25-75}$ Forced expiratory flow at $25 \%$ to $75 \%$ of forced vital capacity (FVC); FEV ${ }_{0.5}, F E V_{0.75}$ and FEV Forced expiratory volume in $0.5 \mathrm{~s}, 0.75 \mathrm{~s}$, and $1 \mathrm{~s}$, respectively; $\mathrm{Rrs}_{5}$ Respiratory resistance at $5 \mathrm{~Hz} ; \mathrm{Xrs}_{5}$ Respiratory reactance at $5 \mathrm{~Hz} ; \triangle$ Changes in measurement after bronchodilator

$\%$ predicted and $\mathrm{FEF}_{25-75} \%$ predicted in parameters of spirometry between the children with or without asthma. After salbutamol administration, there were significant differences in the percentage changes in IOS and spirometry parameters with the exception of Rfo (Table 2).

Quality control was carefully examined for both IOS and spirometry. For IOS, visual control was carefully inspected from the real-time display of tidal flow and/or volume and coherence values at $5 \mathrm{~Hz}$ of $\geq 0.6$ and at $10 \mathrm{~Hz}$ of $\geq 0.9$ were accepted for analysis. For acceptability of spirometry, the differences between the two $\mathrm{FEV}_{1}$ measures before salbutamol were $0.4 \pm 4.5 \%$ and $1.3 \pm 3.5 \%$, respectively. Back extrapolated volume (Vbe) for prebronchodilation and postbronchodilation were $34 \pm 13 \mathrm{~mL}$ and $39 \pm 14 \mathrm{~mL}$, respectively $(\mathrm{P}=0.043)$. Vbe/FVC for prebronchodilation and postbronchodilation were $3.3 \pm 1.2 \%$ and $3.4 \pm 1.0 \%$, respectively. Time to peak expiratory flow for prebronchodilation and postbronchodilation were $0.12 \pm 0.04 \mathrm{~s}$ and $0.11 \pm 0.03 \mathrm{~s}$, respectively.

Table 3 summarizes the changes in $\mathrm{FEV}_{1}, \mathrm{Rrs}_{5}$, and $\mathrm{Xrs}_{5}$ after salbutamol administration, expressed in three different ways: as an absolute difference and as a percentage of initial or predicted values according to a previous study (26). Regardless of the different expressions, significant differences were observed in $\mathrm{FEV}_{1}, \mathrm{Rrs}_{5}$ and $\mathrm{Xrs}_{5}$ among the groups.

The area under the ROC curve (AUC) for BDR of $\triangle \mathrm{FEV}_{1} \%$ init and $\Delta \mathrm{Rrs}_{5} \%$ init were 0.81 (95\% CI 0.70 to 0.93 ) and 0.74 (95\% CI 0.62 to 0.87 ), respectively, which were found to be higher than those of the other parameters. Of these measures, Figure 1 illustrates a ROC curve showing the relationship between sensitivity and specificity of changes in IOS-( $\left.\mathrm{Rrs}_{5}\right): 0.74$ (95\% CI 0.62 to 0.87 ) and spirometry$\left(\mathrm{FEV}_{1}\right): 0.81$ (95\% CI 0.70 to 0.93 ) assessed BDR to detect clinical asthma and indicates that $\mathrm{FEV}_{1}$ demonstrated a better discriminating power than $\mathrm{Rrs}_{5}$ between young children with and without asthma based on BDR.

For comparisons of methods, various cut-off points of BDR for $\mathrm{Rrs}_{5}$, $\mathrm{FEV}_{1}$ or a combination of both, as suggested by the current study and previous studies, were chosen for calculation of sensitivity, specificity and positive likelihood ratio (PLR) (Table 4). The cut-off point closest to the left-hand border and the top border of the ROC space that provided the best possible tradeoff between sensitivity and specificity
TABLE 3

Mean changes in forced expiratory volume in $1 \mathrm{~s}\left(\mathrm{FEV}_{1}\right)$, respiratory resistance at $5 \mathrm{~Hz}\left(\mathrm{Rrs}_{5}\right)$ and respiratory reactance at $5 \mathrm{~Hz}\left(\mathrm{Xrs}_{5}\right)$ after salbutamol administration

\begin{tabular}{cccc}
\hline Group & $\mathrm{FEV}_{1}$ & $\mathrm{Rrs}_{5}$ & $\mathrm{Xrs}_{5}$ \\
\hline Healthy & & & \\
$\Delta$ abs & $0.23^{\star}$ & $-0.16^{\star *}$ & $0.07^{\star * \star}$ \\
& $(0.05$ to 0.41$)$ & $(-0.20$ to -0.12$)$ & $(0.05$ to 0.99$)$ \\
$\Delta \%$ init & $2.45^{\dagger}$ & $-15.55^{\dagger \dagger}$ & $15.15^{\dagger \dagger}$ \\
& $(0.66$ to 4.25$)$ & $(-18.98$ to -12.13$)$ & $(5.92$ to 24.38$)$ \\
$\Delta \%$ pred & $2.39^{\ddagger}$ & $-17.61^{\ddagger \ddagger}$ & $20.03^{\ddagger \neq \ddagger}$ \\
& $(0.57$ to 4.20$)$ & $(-21.63$ to -13.59$)$ & $(13.81$ to 26.25$)$ \\
Stable asthma & & & \\
$\Delta$ abs & $1.043^{\star}$ & $-0.27^{\star *}$ & $0.19^{\star \star *}$ \\
& $(0.75$ to 1.34$)$ & $(-0.33$ to -0.21$)$ & $(0.10$ to 0.27$)$ \\
$\Delta \%$ init & $11.63^{\dagger}$ & $-24.08^{\dagger \dagger}$ & $52.84^{\dagger \dagger \dagger}$ \\
& $(8.01$ to 15.25$)$ & $(-27.58$ to -20.59$)$ & $(18.14$ to 87.55$)$ \\
$\Delta \%$ pred & $10.31^{\ddagger}$ & $-31.59^{\ddagger \neq}$ & $57.13^{\ddagger \neq \neq}$ \\
& $(7.35$ to 13.26$)$ & $(-38.80$ to -24.38$)$ & $(30.11$ to 84.16$)$ \\
\hline
\end{tabular}

Data presented as mean ( $95 \% \mathrm{Cl}$ ). $\Delta$ abs Changes in absolute value of parameter; $\Delta \%$ init Change as a percentage of the initial value of parameter; $\Delta \%$ pred Change as a percentage of the predicted value for the parameter; $\mathrm{Rrs}_{5}$ Respiratory resistance at $5 \mathrm{~Hz} ; \mathrm{Xrs}_{5}$ Respiratory reactance at $5 \mathrm{~Hz}$. Regardless of the different expressions, such as $\Delta a b s, \Delta \%$ init, and $\Delta \%$ pred, significant differences (ie, $P<0.05$ ) were observed in $F E V_{1}, R_{r} s_{5}$, and $X r s_{5}$ between groups. ${ }^{\star} \ddagger P<0.05$ between the two groups

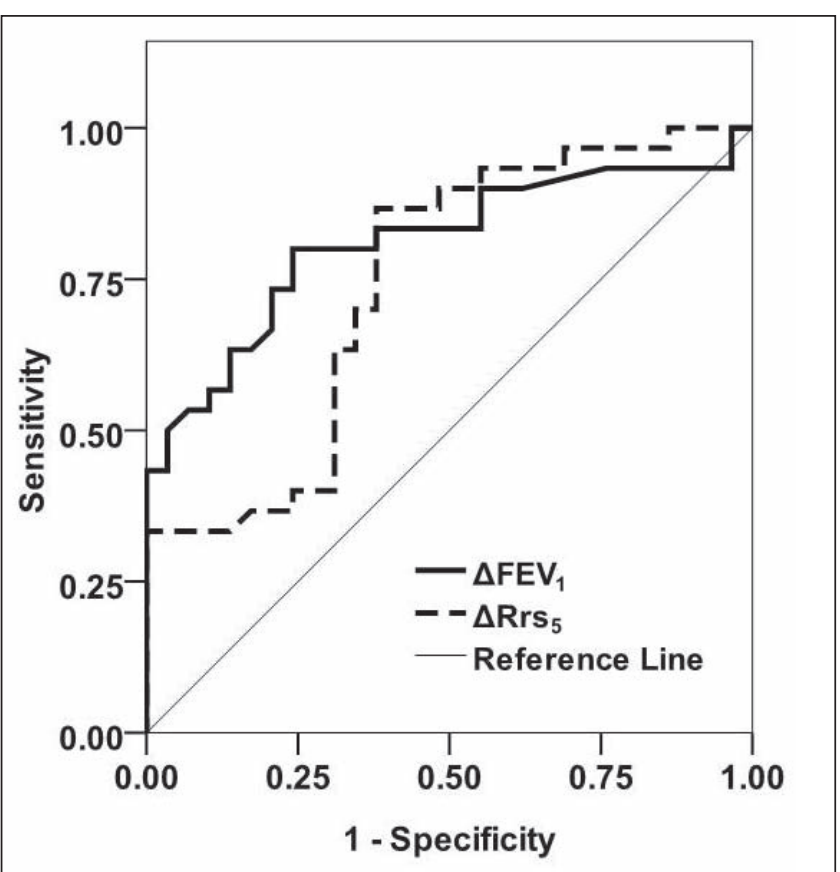

Figure 1) ROC curve showing relationship between sensitivity and 1 - specificity of changes in spirometry (solid line) and in impulse oscillometry - assessed bronchodilator response of resistance at $5 \mathrm{~Hz}$ (Rrs5) (dashed line) to detect clinical asthma. FEV Forced expiratory volume in $1 \mathrm{~s}$

was a $5.3 \%$ change in initial $\mathrm{FEV}_{1}$. At this point, $80 \%$ of the children with asthma showed at least $5.3 \%$ improvement in $\mathrm{FEV}_{1}$ following salbutamol compared with $28 \%$ of controls. The PLR and negative likelihood ratio were 2.90 and 0.28 , respectively. In other words, a BDR of at least $5.3 \%$ multiplies the initial odds in favour of asthma by a factor of 2.9, and a negative test multiplies the initial odds against asthma by a factor of $1 / 0.28=3.6$. The cut-off point of BDR for Rrs was a $15.6 \%$ change in $\mathrm{Rrs}_{5} \%$ init. The PLR and negative likelihood 


\begin{tabular}{|c|c|c|c|c|}
\hline Expression & $\begin{array}{c}\text { Cut-off level, } \\
\% \\
\end{array}$ & Sensitivity & Specificity & $\begin{array}{c}\text { Positive } \\
\text { likelihood ratio }\end{array}$ \\
\hline$\Delta \mathrm{FEV}_{1}{ }^{*}$ & 5.3 & 0.80 & 0.72 & 2.90 \\
\hline$\Delta \operatorname{Rrs}_{5}{ }^{*}$ & 15.6 & 0.87 & 0.62 & 2.29 \\
\hline$\Delta \mathrm{FEV}_{1}{ }^{*}$ or $\Delta \mathrm{Rrs}_{5}{ }^{*}$ & 5.3 or 15.6 & 0.93 & 0.52 & 1.94 \\
\hline$\Delta \mathrm{FEV}_{1}^{\dagger}$ & 9 & 0.53 & 0.93 & 7.73 \\
\hline$\Delta \operatorname{Rrs}_{5}^{\ddagger}$ & 29 & 0.33 & 1 & 0.33 \\
\hline$\Delta \mathrm{FEV}_{1}^{\dagger}$ or $\Delta \mathrm{Rrs}_{5}^{\ddagger}$ & 9 or 29 & 0.63 & 0.93 & 9.14 \\
\hline
\end{tabular}

Number of 'positive' responses with the sensitivity, specificity and likelihood ratio of a positive result for the distinction between asthma and healthy control. ${ }^{*}$ Present study; ${ }^{\dagger}$ Reference $5 ;{ }^{\ddagger}$ Reference $8 . \Delta$ Change as a percentage of the initial value of parameter; FEV 1 Forced expiratory volume in $1 \mathrm{~s}$; Rrs5 Respiratory reactance at $5 \mathrm{~Hz}$

ratio were 2.29 and 0.22 , respectively. Applying either $\Delta \mathrm{FEV}_{1} \geq 5.3 \%$ or $\Delta \mathrm{Rrs}_{5} \geq 15.6 \%$ for the diagnosis of asthma, that is, that either one of the best cut-offs were met increased the sensitivity of diagnosis by $13 \%$ but decreased the specificity by $20 \%$. Applying either $\Delta \mathrm{FEV}_{1} \geq 9 \%$ (5) or $\Delta \mathrm{Rrs}_{5} \geq 29 \%$ (8) for the diagnosis of asthma yielded a sensitivity of 0.63 , a specificity of 0.93 and a PLR of 9.14. Thus, these data suggest that when BDR measured by spirometry was combined with BDR measured by IOS, the results increased the accuracy of the diagnosis.

\section{DISCUSSION}

We found that conventional spirometry is better than IOS at discriminating between children with asthma from healthy subjects on the basis of BDR. We also demonstrated that when BDR obtained by conventional spirometry is combined with that assessed by IOS, confidence in diagnosing asthma is increased, as reflected by the increased AUC. Therefore, IOS may help in diagnosing asthma and can be used as a diagnostic tool supplementary to spirometry.

Generally, a test is considered to be discriminative if the AUC $>0.70$ (27). In the present study, the AUCs for all measures tested showed values $>0.70$ except $\triangle \mathrm{AX} \%$, and spirometry measures were found to be higher than IOS measures, thus suggesting that BDR tests measured using spirometry and IOS are useful for identifying preschool children with asthma and that spirometry has a better discriminative power than IOS in diagnosing preschool children with asthma. When BDR of $\triangle \mathrm{FEV}_{1} \%$ init $\geq 9 \%$ (5) alone was considered for the diagnosis of asthma, the PLR was 7.73. When BDR of $\triangle \mathrm{FEV}_{1} \%$ init $\geq 9 \%$ was combined with that of $\Delta \operatorname{Rrs}_{5} \%$ init $\geq 29 \%$, (8) the PLR increased to 9.14 , which clearly indicates that although spirometry has a better discriminative power than IOS, IOS may help to better discriminate between asthmatic preschool children and controls.

The results of the present study are in contrast to those of previous studies $(11,12)$, which asserted that IOS was better than spirometry at discriminating between young children with and without asthma on the basis of their BDR. In those studies $(11,12)$ concurrent asthma was determined using American Thoracic Society (ATS)-Bronchial asthma (ATS-B) criteria (28), whereas in the present study, asthma diagnosis was made by an experienced pediatrician. Although ATS-B criteria were shown to be valid (11), we speculate that they cannot replace asthma diagnosis made by an experienced pediatrician. A study by Olaguibel et al (13) suggested that $\mathrm{Rrs}_{5}$ values correlated well with spirometry $\left(\mathrm{FEV}_{1}\right)$ on the basis of BDR. However, this study did not include control subjects.

The reliability of spirometry depends on standardized methodology; quality control criteria were published by the ATS and Eureopean Respiratory Society (ERS) (4). Because preschool children have difficulty meeting some criteria, the following quality control criteria suitable for that age group were proposed for acceptability: Vbe $\leq 80 \mathrm{~mL}$ and $\leq 12.5 \%$ of FVC (14), time to PEF $<160 \mathrm{msec}$ (21); and for repeatability: difference $(\Delta)$ between the two $\Delta \mathrm{FEV}_{1} \leq 110 \mathrm{~mL}$ and $10 \%$ of best effort, and difference between the two $\Delta \mathrm{FVC} \leq 110 \mathrm{~mL}$ and $10 \%$ of best effort (15). The preschool children included in the present study were able to meet these criteria because children who produced acceptable manoeuvres in a previous study were asked to enroll. For IOS, it is recommended to use a coherence value of $\mathrm{Y}^{2} \geq 0.6$ at $5 \mathrm{~Hz}$ for the acceptance threshold. Coherence improves as a function of oscillatory frequency to $\mathrm{Y}^{2} \geq 0.9$ at frequencies of $\geq 10 \mathrm{~Hz}$ (29). Therefore, in the present study, only data that qualified under these criteria were used for analyses.

The cut-off point for $\mathrm{FEV}_{1}$ BDR of our asthmatic subjects was $5.3 \%$, whereas previous studies have suggested cut-off points of $\mathrm{FEV}_{1}$ BDR to range from a $7.8 \%$ to a $9 \%$ increase $(5,6)$, indicating that there is no clear consensus about what constitutes significant reversibility in subjects with airflow obstruction using spirometry. According to a $\geq 9 \%$ increase criterion (5), we found that 17 of 30 children $(56.7 \%$ ) with asthma had a positive BDR. This is consistent with a previous report that a large proportion of patients with asthma do not show a positive BDR (22). For IOS measurements, the cut-off point of $\mathrm{Rrs}_{5}$ BDR of our asthmatic subjects, expressed in $\Delta \mathrm{Rrs}_{5} \%$ init, was $15.6 \%$. Values for IOS BDR deemed reliable for the diagnosis of asthma have been reported to range from a $20 \%$ to $40 \%$ decrease in $\operatorname{Rrs}_{5}(8,9)$.

The cut-off points of BDR for $\mathrm{FEV}_{1}(5,6,8,9)$ and $\mathrm{Rrs}_{5}(8,9)$ in the present study were found to be relatively lower than those suggested in previous studies $(5,6,8,9)$. The difference in cut-off points between the present study and previous studies could be ascribed to the fact that the healthy control subjects in the present study were strictly defined according to recommendations by Stocks et al (18). Furthermore, 378 subjects with risk factors that may have influenced bronchial reactivity, such as a history of wheezing, atopic dermatitis, allergic rhinitis or a family history of asthma, were also excluded $(19,20)$. To the best of our knowledge, the present study was the first to demonstrate BDRs in healthy preschool children defined by Stocks et al (18) in an effort to exclude subjects with risk factors that may have an effect on BDR. Therefore, exclusion of subjects with any risk factors that directly or indirectly influence the respiratory system and general state of health may have allowed the relatively small values to be the cut-off points for differentiating the disease group from controls. Because we used a strict definition of 'healthy', caution should be exercised in applying these low cut-off points of BDR derived from IOS and spirometry to a general population.

Seven of 29 healthy children (24\%) in our study population showed a positive BDR of $>5.3 \%$ by spirometry. In a previous study comparing BDR in children eight to 15 years of age with asthma (20), children without asthma from asthma index families and random control subjects, the proportion of children with positive BDR (>12\%) was $21 \%, 10 \%$ and $9 \%$, respectively, demonstrating that a portion of subjects without asthma show a positive BDR. The reason that our study showed a higher proportion of subjects with a positive BDR could be ascribed to the fact that the study mentioned above defined a positive $\mathrm{BDR}$ as values $>12 \%$, whereas our study defined a positive $\mathrm{BDR}$ as values $>5.3 \%$. If $\mathrm{BDR}>12 \%$ was chosen as positive in our healthy subjects, no children would have shown a positive BDR.

Strengths of our study are as follows: it was the first to demonstrate BDR in strictly defined healthy control subjects, and quality control criteria for IOS and spirometry (15) were applied in preschool children. Limitations of our study included the relatively small number of subjects compared with previous studies; the control subjects were selected from the general population whereas the asthma subjects were recruited from a group of patients who were followed-up at our institution. Furthermore, because asthmatic subjects classified into different levels of disease severity were included, their pulmonary function measurements may have yielded different results, thus making data interpretation difficult. 


\section{CONCLUSION}

In the present study, we found that with quality control criteria for lung function measurements applied to preschool children, spirometry was better than IOS at discriminating between young children with and without asthma on the basis of their BDR. Furthermore, to increase the accuracy of diagnosis, IOS can be used in patients who show a negative BDR by spirometry. Although spirometry was found to be superior to IOS, IOS is a promising test to identify asthmatic preschoolers because it has some advantages over spirometry and, therefore, may be used as a supplementary tool in diagnosing asthma. Our data build on previous work by suggesting the level of a positive IOS $\mathrm{BDR}$ to be a $15.6 \%$ decrease in $\mathrm{Rrs}_{5}$ in asthmatic preschool children.

DISCLOSURE: The authors have no financial disclosures or conflicts of interest to declare.

ACKNOWLEDGEMENTS: The authors thank Da Woon Jung for performing PFT on children and the Korean Academy of Pediatric Allergy and Respiratory Diseases for providing the Korean version of ISAAC protocol.

\section{REFERENCES}

1. Expert Panel Report 3 (EPR-3): Guidelines for the Diagnosis and Management of Asthma-Summary Report 2007. J Allergy Clin Immunol 2007;120(5 Suppl):S94-138.

2. Pellegrino R, Sterk PJ, Sont JK, Brusasco V. Assessing the effect of deep inhalation on airway calibre: A novel approach to lung function in bronchial asthma and COPD. Eur Respir J 1998;12:1219-27.

3. Nadel JA, Tierney DF. Effect of a previous deep inspiration on airway resistance in man. J Appl Physiol 1961;16:717-9.

4. Beydon N, Davis SD, Lombardi E, et al. An official American Thoracic Society/European Respiratory Society statement: Pulmonary function testing in preschool children. Am J Respir Crit Care Med 2007;175:1304-45.

5. Dundas I, Chan EY, Bridge PD, McKenzie SA. Diagnostic accuracy of bronchodilator responsiveness in wheezy children. Thorax 2005;60:13-6

6. Kjaer HF, Eller E, Bindslev-Jensen C, Host A. Spirometry in an unselected group of 6-year-old children: The DARC birth cohort study. Pediatr Pulmonol 2008;43:806-14.

7. Houghton CM, Woodcock AA, Singh D. A comparison of lung function methods for assessing dose-response effects of salbutamol. Br J Clin Pharmacol 2004;58:134-41.

8. Nielsen KG, Bisgaard H. Discriminative capacity of bronchodilator response measured with three different lung function techniques in asthmatic and healthy children aged 2 to 5 years. Am J Respir Crit Care Med 2001;164:554-9.

9. Hellinckx J, De Boeck K, Bande-Knops J, van der Poel M, Demedts M. Bronchodilator response in 3-6.5 years old healthy and stable asthmatic children. Eur Respir J 1998;12:438-43.

10. Thamrin C, Gangell CL, Udomittipong K, et al. Assessment of bronchodilator responsiveness in preschool children using forced oscillations. Thorax 2007;62:814-9.
11. Marotta A, Klinnert MD, Price MR, Larsen GL, Liu AH. Impulse oscillometry provides an effective measure of lung dysfunction in 4-year-old children at risk for persistent asthma. J Allergy Clin Immunol 2003;112:317-22.

12. Song TW, Kim KW, Kim ES, Park JW, Sohn MH, Kim KE. Utility of impulse oscillometry in young children with asthma. Pediatr Allergy Immunol 2008;19:763-8.

13. Olaguibel JM, Alvarez-Puebla MJ, Anda M, et al. Comparative analysis of the bronchodilator response measured by impulse oscillometry (IOS), spirometry and body plethysmography in asthmatic children. J Investig Allergol Clin Immunol 2005;15:102-6.

14. Aurora P, Stocks J, Oliver C, et al. Quality control for spirometry in preschool children with and without lung disease. Am J Respir Crit Care Med 2004;169:1152-9.

15. Neve V, Edme JL, Devos P, et al. Spirometry in 3-5-year-old children with asthma. Pediatr Pulmonol 2006;41:735-43.

16. Park JH, Yoon JW, Shin YH, et al. Reference values for respiratory system impedance using impulse oscillometry in healthy preschool children. Korean J Pediatr 2011;54:64-8.

17. Hong SJ, Ahn KM, Lee SY, Kim KE. The prevalences of asthma and allergic diseases in Korean children. Korean J Pediatr 2008;51:343-50.

18. Stocks J, Quanjer PH. Reference values for residual volume, functional residual capacity and total lung capacity. ATS Workshop on Lung Volume Measurements. Official Statement of The European Respiratory Society. Eur Respir J 1995;8:492-506.

19. Capasso M, Varricchio A, Ciprandi G. Impact of allergic rhinitis on asthma in children: Effects on bronchodilation test. Allergy 2010;65:264-8.

20. Kumar R, Wang B, Wang X, et al. Bronchodilator responses in Chinese children from asthma index families and the general population. J Allergy Clin Immunol 2006;117:1257-63.

21. Enright PL, Linn WS, Avol EL, Margolis HG, Gong H Jr, Peters JM. Quality of spirometry test performance in children and adolescents: Experience in a large field study. Chest 2000;118:665-71.

22. Suh DI, Lee JK, Kim CK, Koh YY. Bronchial hyperresponsiveness to methacholine/AMP and the bronchodilator response in asthmatic children. Eur Respir J 2011;37:800-5.

23. Kim HY, Shin YH, Jung da W, Jee HM, Park HW, Han MY. Resistance and reactance in oscillation lung function reflect basal lung function and bronchial hyperresponsiveness respectively. Respirology 2009;14:1035-41.

24. Dencker M, Malmberg LP, Valind S, et al. Reference values for respiratory system impedance by using impulse oscillometry in children aged 2-11 years. Clin Physiol Funct Imaging 2006;26:247-50.

25. Waalkens HJ, Merkus PJ, van Essen-Zandvliet EE, et al. Assessment of bronchodilator response in children with asthma. Dutch CNSLD Study Group. Eur Respir J 1993;6:645-51.

26. Postma DS, Gimeno F, van der Weele LT, Sluiter HJ. Assessment of ventilatory variables in survival prediction of patients with chronic airflow obstruction: The importance of reversibility. Eur J Respir Dis 1985;67:360-8.

27. Hanley JA, McNeil BJ. The meaning and use of the area under a receiver operating characteristic (ROC) curve. Radiology 1982;143:29-36.

28. Joseph CL, Foxman B, Leickly FE, Peterson E, Ownby D. Sensitivity and specificity of asthma definitions and symptoms used in a survey of childhood asthma. J Asthma 1999;36:565-73.

29. Smith H, Reinhold P, Goldman M. Forced oscillation technique and impulse oscillometry. Eur Respir Monogr 2005;31:72. 


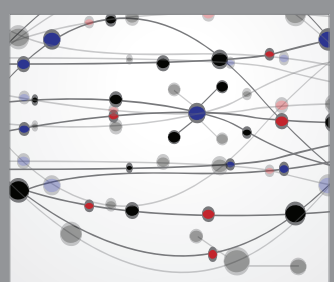

The Scientific World Journal
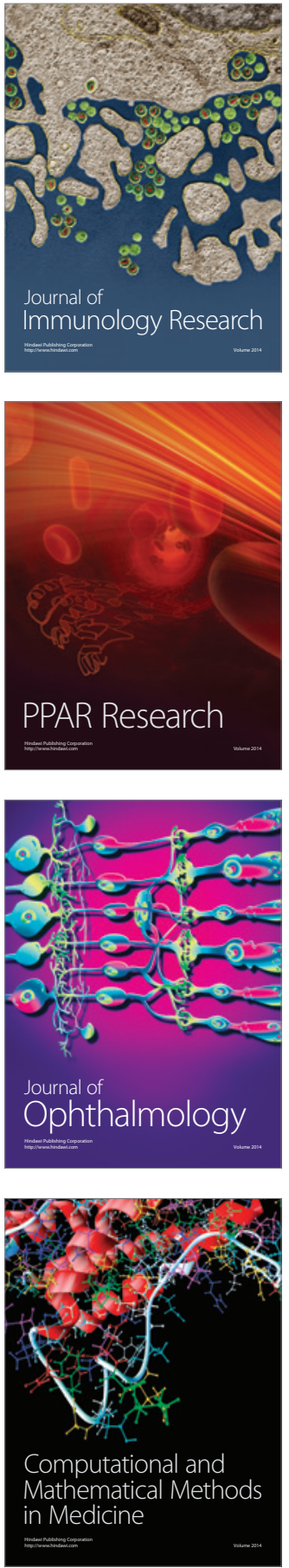

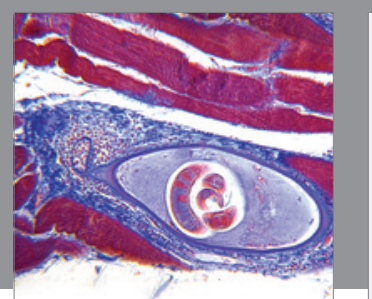

Gastroenterology Research and Practice

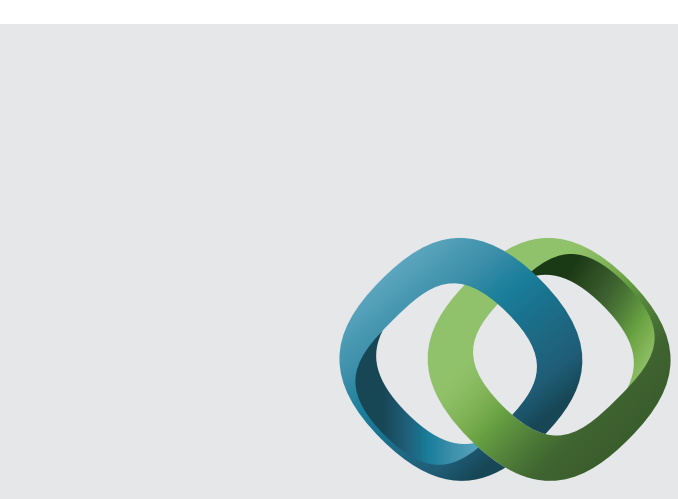

\section{Hindawi}

Submit your manuscripts at

http://www.hindawi.com
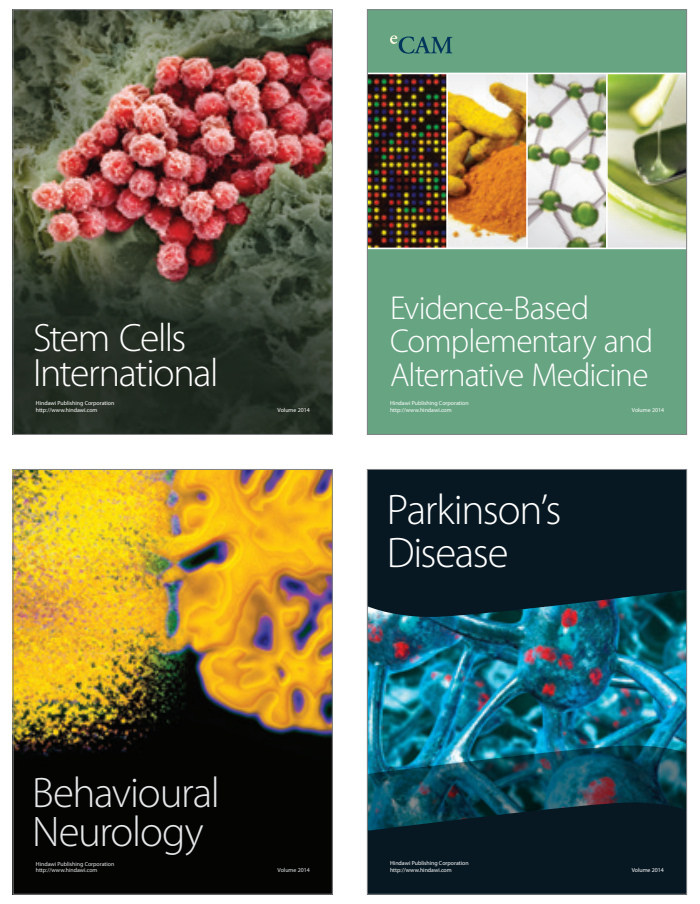
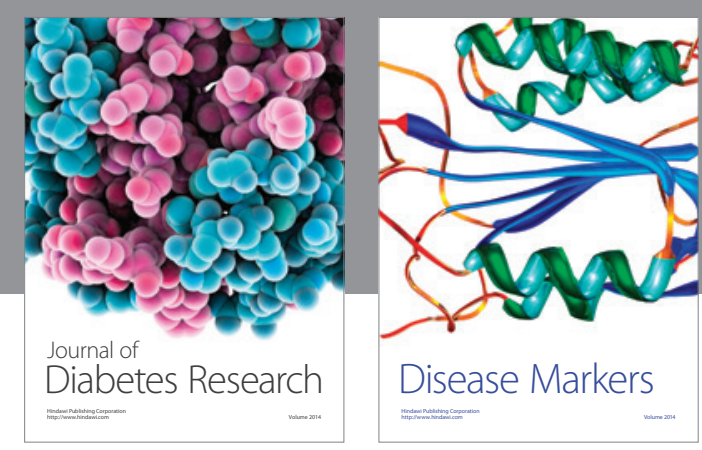

Disease Markers
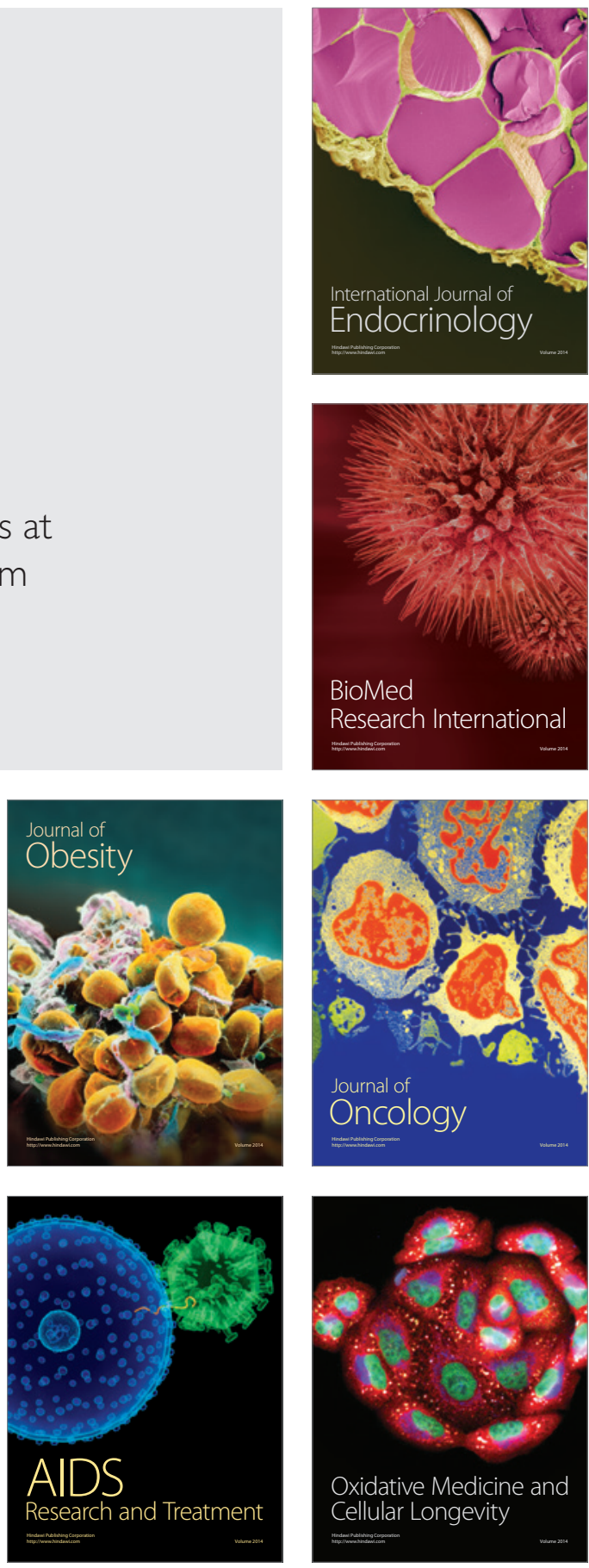